\title{
Influence of Cavitation in Common-Rail Diesel Nozzles on the Soot Formation Process through Measuring Soot Emissions
}

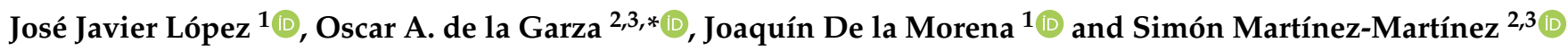 \\ 1 CMT-Motores Térmicos, Universitat Politècnica de València, Camino de Vera s/n, 46022 Valencia, Spain; \\ jolosan3@mot.upv.es (J.J.L.); joadela@mot.upv.es (J.D.1.M.) \\ 2 Laboratory for Research and Innovation in Energy Technology (LITE), Facultad de Ingeniería Mecánica y \\ Eléctrica (FIME), Universidad Autónoma de Nuevo León, Av. Universidad s/n, Ciudad Universitaria, \\ San Nicolás de los Garza 66455, Nuevo León, Mexico; simon.martinez@uanl.edu.mx \\ 3 Laboratorio Nacional de Desarrollo y Aseguramiento de la Calidad de Biocombustibles (LaNDACBio), \\ Av. Universidad s/n, Ciudad Universitaria, San Nicolás de los Garza 66455, Nuevo León, Mexico \\ * Correspondence: oscar.delagarzadl@uanl.edu.mx; Tel.: +52-81-8329-4000 (ext. 1636)
}

Citation: López, J.J.; de la Garza, O.A.; De la Morena, J.;

Martínez-Martínez, S. Influence of Cavitation in Common-Rail Diesel Nozzles on the Soot Formation Process through Measuring Soot Emissions. Energies 2021, 14, 6267. https://doi.org/10.3390/en14196267

Academic Editor: Octavio Armas

Received: 8 July 2021

Accepted: 15 September 2021

Published: 1 October 2021

Publisher's Note: MDPI stays neutral with regard to jurisdictional claims in published maps and institutional affiliations.

Copyright: (c) 2021 by the authors. Licensee MDPI, Basel, Switzerland. This article is an open access article distributed under the terms and conditions of the Creative Commons Attribution (CC BY) license (https:// creativecommons.org/licenses/by/ $4.0 /)$.

\begin{abstract}
The influence of cavitation in common-rail diesel nozzles on the soot formation process has been analysed experimentally. The soot formation process was characterized by measuring soot emissions in a single-cylinder engine, which was mounted on a test bench equipped with an opacimeter. In order to do this, operating conditions where the soot oxidation process was equivalent were chosen, whereby differences in the soot formation process were possible to be analysed. The results achieved confirm that cavitation provokes a soot formation process reduction. This reduction can be attributed by combining results of three effects: a reduction of the effective diameter, an increase in effective injection velocity, and an increase in turbulence level inside the nozzle orifice leading to a longer lift-off length. The three effects lead to a decrease in relative fuel/air ratio at the lift-off, therefore explaining the soot formation reduction.
\end{abstract}

Keywords: diesel nozzle; cavitation; combustion process; soot emissions; soot formation process

\section{Introduction}

Soot emissions are one of the main pollutants from diesel engines, which are regulated by environmental regulations [1-5]. Soot emissions are the result of a balance between the soot formation process and that of soot oxidation [6]. One of the alternatives to decrease these soot emissions is to reduce their formation. According to López et al. [7], Pires et al. [8], and $\mathrm{Xu}$ et al. [9], the soot formation process depends mainly on the relative fuel/air ratio at the lift-off length.

Several studies have focused on analysing the influence on the lift-off length and its influence on the soot formation process of diverse parameters, namely, the in-cylinder air density and temperature $[10,11]$, the injection pressure [11,12], the nozzle orifice diameter [13], the nozzle geometry [14], and the oxygen concentration [15]. Concerning the nozzle geometry, a physical phenomenon called cavitation can appear or not, depending on the nozzle geometry and operating conditions, such as injection pressure and backpressure. To be more precise, this physical phenomenon appears due to a local pressure drop at the inlet of the nozzle hole as a consequence of the increase in fuel flow velocity inside the injector, provoked by the high injection pressure levels employed [16]. It is well known that this phenomenon has positive effects on different parameters such as the nozzle effective diameter, the effective injection velocity, and the mixing process. For instance, López et al. [17], investigated the effects of cavitation on the nozzle effective diameter, the effective injection velocity, and the spray cone angle. They reported that the nozzle effective diameter decreases with the increase in the cavitation level, as well as, that cavitation provokes an increase in both injection velocity and spray cone angle, which 
lead to an improvement in the mixing process. Salvador et al. [18], analysed the hydraulic performance of three diesel nozzles with different degrees of conicity, and observed also an increase in the effective injection velocity, when the cavitation phenomenon appears. Similarly, Guo et al. [19], investigated the effects of the internal flow in an optical diesel nozzle on the spray behaviour under cavitating conditions. They also observed that cavitation provokes a remarkable increase in the spray cone angle.

The positive effects aforementioned provoked by cavitation are the main reason why several works have focused on studying the impact of cavitation on the combustion process. Some of these works studied the impact of cavitation on soot emissions. For instance, Fimml et al. [20] investigated the influence of cavitation in diesel nozzles on the combustion process and they observed remarkable differences in both burn rates and soot emissions, where the soot emissions values of the cavitating nozzle are higher than those of the non-cavitating nozzle. Benajes et al. [21] studied the effects of nozzle orifice convergence, and cavitation on the combustion process. They found that both convergence and cavitation provoke an improvement of the mixing process, hence, reducing soot emissions. Other studies analysed the impact of cavitation on the soot formation process by measuring the soot radiation. For example, Som et al. [22] investigated the influence of the diesel nozzle geometry on the injection and combustion processes through the correlation between the internal flow and spray simulations, and observed that the lift-off length values of the cylindrical nozzle are higher than those of the conical nozzle, provoking a soot formation reduction. Similarly, Maes et al. [23], analysed the influence of cavitation on the mixing and combustion processes, utilizing n-dodecane and two diesel nozzles, one of them promoting the appearance of the cavitation phenomenon, whilst the other one preventing this phenomenon. They found that the soot values of the cavitating nozzle are higher than those of the non-cavitating nozzle, attributing their result to the higher equivalence ratio at the lift-off length. However, they also observed an opposite trend at low temperatures due to the different mixing processes. In a previous work [24] performed by the present authors, the effect of cavitation on the lift-off length and soot formation process was also analysed by measuring the soot radiation and using a non-cavitating nozzle and a cavitating nozzle. They confirmed that cavitation provokes an increase in the effective injection velocity and a decrease in the nozzle effective diameter, finding also that cavitation provokes an increase in the lift-off length. Hence, because of this increased distance, the equivalence ratio at the lift-off length was reduced, leading to a reduction in soot formation. In addition, it is worthy to note that there are very limited studies that analyse these aspects through measuring soot emissions.

In order to clarify these controversial results presented by the last cited authors, it is important to improve the comprehension of the influence of cavitation on the soot formation process. Therefore, the present work aims to address the impact of cavitation on the soot formation process through measuring engine-out soot emissions in a single-cylinder engine with the use of an opacimeter. For doing so, some operating conditions where the soot oxidation process is equivalent will be chosen, whereby it will be possible to analyse differences in the soot formation process. More details about this novel methodology will be presented later. Moreover, the same diesel nozzles presented in [24] will be employed, making use, when necessary, of the results also reported in [24]. Finally, it is expected that cavitation provokes a reduction in soot formation.

\section{Materials and Methods}

2.1. Materials

2.1.1. Nozzles and Fuel

Two nozzles with three orifices, which were installed in a piezoelectric diesel injector holder were used. One of them prevents the appearance of the cavitation phenomenon, whilst the other one exhibits and promotes this phenomenon. The nozzles studied have 
different degrees of conicity. The degree of conicity is characterized by the k-factor, which is defined by Equation (1) [17]:

$$
\mathrm{k} \text {-factor }=\frac{\left(d_{\text {in }}-d_{\text {out }}\right)[\mu \mathrm{m}]}{10}
$$

where $d_{\text {out }}$ is the nozzle orifice outlet diameter and $d_{i n}$ is the nozzle orifice inlet diameter.

In a previous study by Payri et al. [24], both nozzles were first used. In Table 1, the geometrical details of the nozzles which were determined by utilizing the silicone methodology [25] are synthetized.

Table 1. Geometrical details of the nozzles employed in the study [24].

\begin{tabular}{cccc}
\hline Nozzle & $\boldsymbol{d}_{\boldsymbol{i n}}[\boldsymbol{\mu \mathrm { m }}]$ & $\boldsymbol{d}_{\text {out }}[\boldsymbol{\mu \mathrm { m }}]$ & k-Factor [-] \\
\hline Conical nozzle & 135 & 105 & 3 \\
Cylindrical nozzle & 122 & 122 & 0 \\
\hline
\end{tabular}

Standard diesel fuel was used in all experiments, whose density and kinematic viscosity are $842.1 \mathrm{~kg} / \mathrm{m}^{3}$ and $2.820 \times 10^{-6} \mathrm{~m}^{2} / \mathrm{s}$, determined according to EN ISO $12185 / 96$ at $15^{\circ} \mathrm{C}$ and EN ISO $3104 / 99$ at $40^{\circ} \mathrm{C}$, respectively.

\subsubsection{Single-Cylinder Engine and Opacimeter}

The single-cylinder engine is equivalent to the engines used in passenger cars. It is derived from the PSA Peugeot-Citroën engine DV6-TED4. In addition, it has a multivalve cylinder head (four valves per cylinder). The technical specifications of the single-cylinder engine are described in Table 2. The engine was mounted in a test bench, with the components necessary for its proper operation, as is shown in Figure 1. More details about the test bench are available in [26]. In addition, in Table 3, the operating conditions employed in the tests are described.

Table 2. Technical specifications of the single-cylinder engine DV6-TED4.

\begin{tabular}{cc}
\hline Characteristic & Value \\
\hline Bore & $75.1 \mathrm{~mm}$ \\
Stroke & $88.0 \mathrm{~mm}$ \\
Displacement volume & $399 \mathrm{~cm}^{3}$ \\
Connecting rod length & $123.8 \mathrm{~mm}$ \\
Bowl diameter & $46.3 \mathrm{~mm}$ \\
Depth of bowl & $14.3 \mathrm{~mm}$ \\
Compression ratio & 16.5 \\
Exhaust valve diameter & $23.4 \mathrm{~mm}$ \\
Intake valve diameter & $25.6 \mathrm{~mm}$ \\
Swirl number & 2.15 \\
Bowl volume & $18.3 \mathrm{~cm}^{3}$ \\
Number of valves per cylinder & 4 \\
\hline
\end{tabular}

Table 3. Operating conditions employed in the tests.

\begin{tabular}{cc}
\hline Parameter & Value \\
\hline Engine speed & $1000 \mathrm{rpm}$ \\
Intake pressure & $0.15 \mathrm{MPa}$ \\
Intake temperature & $45^{\circ} \mathrm{C}$ \\
Backpressure at exhaust gas line & $0.16 \mathrm{MPa}$ \\
Water temperature & $80^{\circ} \mathrm{C}$ \\
Oil temperature & $90{ }^{\circ} \mathrm{C}$ \\
Fuel temperature & $40^{\circ} \mathrm{C}$ \\
Injection pressure & $76 \mathrm{MPa}$ and $146 \mathrm{MPa}$ \\
F/A equivalence ratio & 0.6 \\
\hline
\end{tabular}




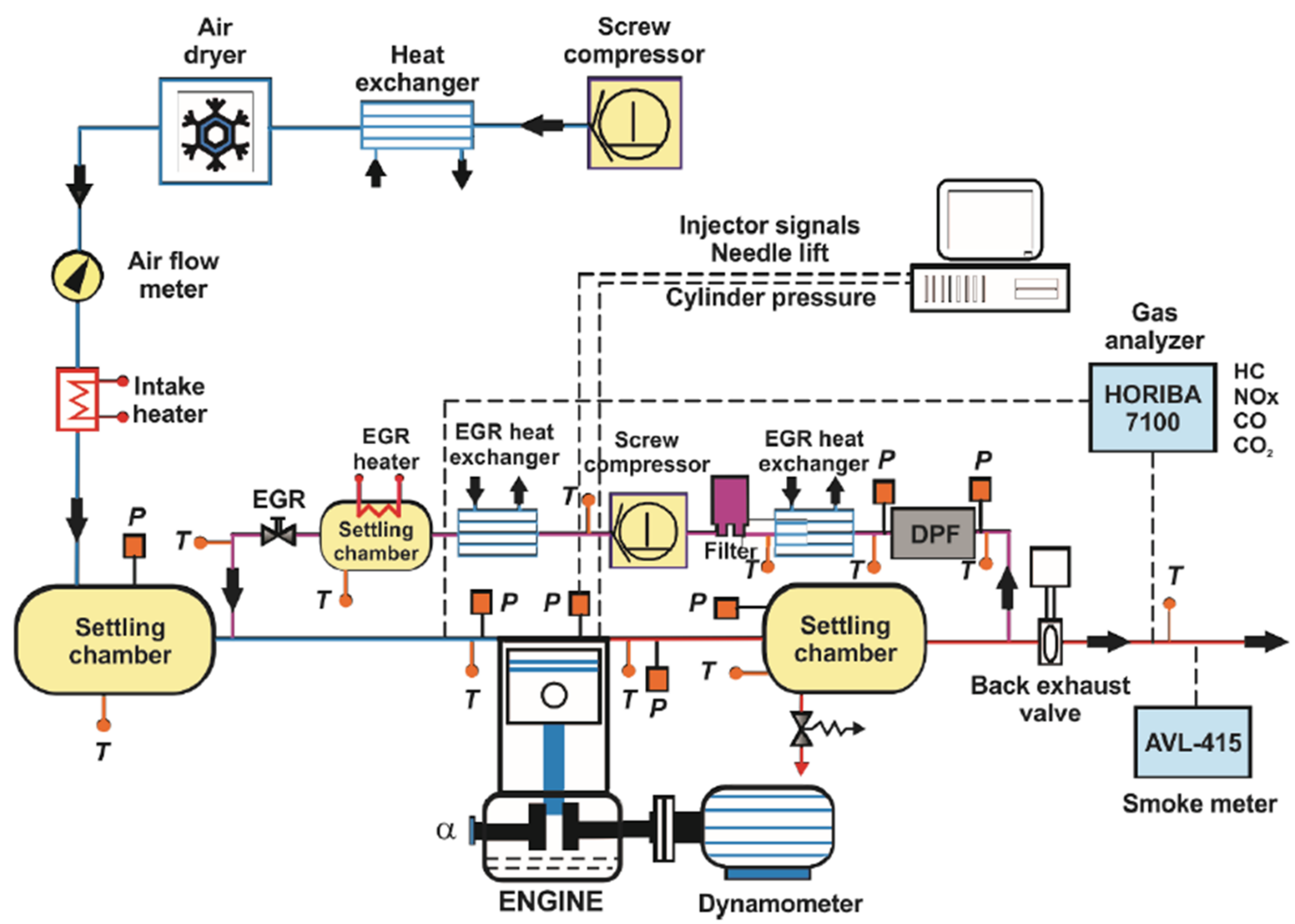

Figure 1. Complete test bench setup, adapted from Olmeda et al. [26].

The opacimeter used was an AVL 415. Its measuring principle consists in passing a sample of exhaust gases through a white paper filter with a known light reflection index, and subsequently through a photoelectric cell. The darkening degree of the paper previously mentioned depends mainly on the soot concentration, which is the parameter finally determined. Hence, the smoke measurement is based on the comparison of the light reflection index. The scale of the equipment is comprised between a minimum value $(0$ FSN) and the absolutely black paper (10 FSN), where FSN (Filter Smoke Number) is the unit assigned to the scale, previously mentioned. By means of Equation (2) it is possible to convert the FSN unit into $\mathrm{mg} / \mathrm{m}^{3}$ [27].

$$
\text { Soot }\left[\frac{\mathrm{mg}}{\mathrm{m}^{3}}\right]=\frac{1}{0.405} \cdot 4.95 \cdot \operatorname{smoke}[F S N] \cdot e^{(0.38 \cdot s m o k e[F S N])}
$$

It is worthy to note that Equation (2), which is similar to that developed by Christian et al. [28], has been used in the present research for the units conversion. In addition, it is important to mention that the sample is extracted at nearly atmospheric pressure from the exhaust system, and the amount of sample is controlled directly by the equipment. Besides, the gas sample is cooled down up to ambient temperature before passing through the paper filter. The soot emission index $\left(I_{\text {soot }}\right)$ can be expressed in $g / k_{f u e l}$ by Equation (3) [27].

$$
I_{\text {Soot }}\left[\frac{\mathrm{g}}{\mathrm{kg}_{\text {fuel }}}\right]=\left(\frac{\text { Soot }\left[\frac{\mathrm{mg}}{\mathrm{m}^{3}}\right] / 1000}{m_{f}[\mathrm{~kg} / \mathrm{h}]}\right) \cdot \frac{\left(\text { VolumetricFlowRateExhausGases }\left[\frac{\mathrm{m}^{3}}{\mathrm{~h}}\right]\right)}{)}
$$

The VolumetricFlowRateExhaustGases is calculated by Equation (4) [28].

$$
\text { VolumetricFlowRateExhaustGases }\left[\mathrm{m}^{3} / \mathrm{h}\right]=\frac{\left(\dot{m}_{f}+\dot{m}_{a}\right)[\mathrm{kg} / \mathrm{h}]}{\rho_{\text {ref }}\left[\mathrm{kg} / \mathrm{m}^{3}\right]}
$$


where $\dot{m}_{f}$ is the mass flow rate of fuel, $\dot{m}_{a}$ is the mass flow rate of air, and $\rho_{r e f}$ is the reference density, which is $1.2 \mathrm{~kg} / \mathrm{m}^{3}$, value obtained at the temperature and pressure in that the opacimeter performs the measurement. In the present work the $\rho_{\text {ref }}$ has been assumed constant.

It is worthy to note that in the present work, the soot emissions measured in the engine are converted to the mass values through Equation (3).

\subsubsection{Combustion Diagnostic Model}

The combustion diagnostic model called CALMEC [29] was employed. Zero-dimensional and single-zone are the main characteristics of this model, as well as the fact that it is based on the solution of the first law of thermodynamics for an open system, and on the state equation. For simplicity, in this model it is considered that pressure and temperature are uniform inside the cylinder. The main parameters obtained from the model were the Heat Release Fraction (HRF), which is associated with the thermal energy released during the combustion process and it depends on both crank angle and some additional information related to each engine cycle. More specifically, the start of combustion, defined as the crank angle position in which $2 \%$ of cumulated heat has been released, was obtained. Additional information related to the CALMEC model is available in [29].

\subsection{Methods}

\subsubsection{Hydraulic Characterization}

From the hydraulic characterization of the diesel nozzles previously performed and reported by Payri et al. [24], flow characteristics parameters such as velocity coefficient $C_{v}$, which characterizes the effective injection velocity, and nozzle effective diameter $d_{e f f}$ were determined. The flow characteristic parameters are described in Table 4.

Table 4. Flow characteristic parameters.

\begin{tabular}{cccc}
\hline Nozzle & $C_{v}[-]$ & $d_{\text {eff }}[\mathrm{mm}]$ & Operating Conditions \\
\hline Conical nozzle & $0.84 / 0.85$ & $0.099 / 0.099$ & $\begin{array}{c}\text { Injection pressure: } 76 / 146 \mathrm{MPa} \\
\text { back pressure } 6 \mathrm{MPa}\end{array}$ \\
Cylindrical nozzle & $0.78 / 0.80$ & $0.112 / 0.109$ & Injection pulse $4 \mathrm{~ms}$ \\
\hline
\end{tabular}

\subsubsection{Soot Formation Process Characterization from the Soot Emissions}

The soot formation process will be characterized from the soot emissions measurement. For this, a single-cylinder engine and an opacimeter, previously described in Section "Single-cylinder engine and opacimeter", will be employed. With regard to the testing methodology, different aspects can be highlighted: (1) the operating condition employed in the engine when using the conical and cylindrical nozzles were the same: the operating conditions have been previously described in Table 3. (2) In order to work with an identical global fuel/air ratio (FAR) in both nozzles and with both $p_{\text {rail }}$ levels of $76 \mathrm{MPa}$ and $146 \mathrm{MPa}$, the same fuel mass has been injected. (3) An injection pulse of around $2 \mathrm{~ms}$ has been used to ensure a diffusion combustion phase, i.e., combustion controlled by mixing. (4) Finally, in order to vary the relative position of the combustion process in the cycle, when utilizing the studied nozzles and $p_{\text {rail }}$ levels of $76 \mathrm{MPa}$ and $146 \mathrm{MPa}$, a sweep of injection timings was performed.

\subsubsection{Methodology for Analysis of the Results}

The methodology is based on establishing a criterion allowing to ensure an equivalent oxidation process in the cases to be compared, to analyse possible differences in the soot formation process. To do so, Molina's work [27] will be considered, where $T_{b-75 \%}$ is proposed as the temperature representative of oxidation at end-of-combustion, when $75 \%$ of the total heat has been released, and this parameter correlated quite well with the final soot emissions at a given operating point, particularly when the start of injection (SOI) was 
swept. In the present work, since cases with the same injected fuel mass and under the same engine operating conditions are compared, the same $T_{b-75 \%}$ is achieved if the cases taken for comparison have the same $C A 75$, i.e., with the same position of the combustion process in the cycle, where $75 \%$ of the fuel mass has been burned. Besides, this also guarantees the same oxygen content in the compared cases, these two parameters (temperature and oxygen concentration) being the main controllers of the soot oxidation process. With this methodology, an equivalent soot oxidation capacity is warranted, and differences in the soot formation process could be observed when analysing the final soot emissions.

The CA75 was obtained through the heat release fraction, which was determined by employing the combustion diagnostic model, CALMEC previously described in the "Combustion diagnostic model" section. The evolution of the HRF (non-dimensional) as a function of the crank angle is shown in Figure 2, for several injection timings viz. $-2.4^{\circ}$, $-0.4^{\circ},+1.6^{\circ},+3.6^{\circ},+5.6^{\circ},+7.6^{\circ},+9.6^{\circ}$, and $+11.6^{\circ}$ After Top Dead Center (ATDC), when using the conical nozzle and a $p_{\text {rail }}$ level of $146 \mathrm{MPa}$.

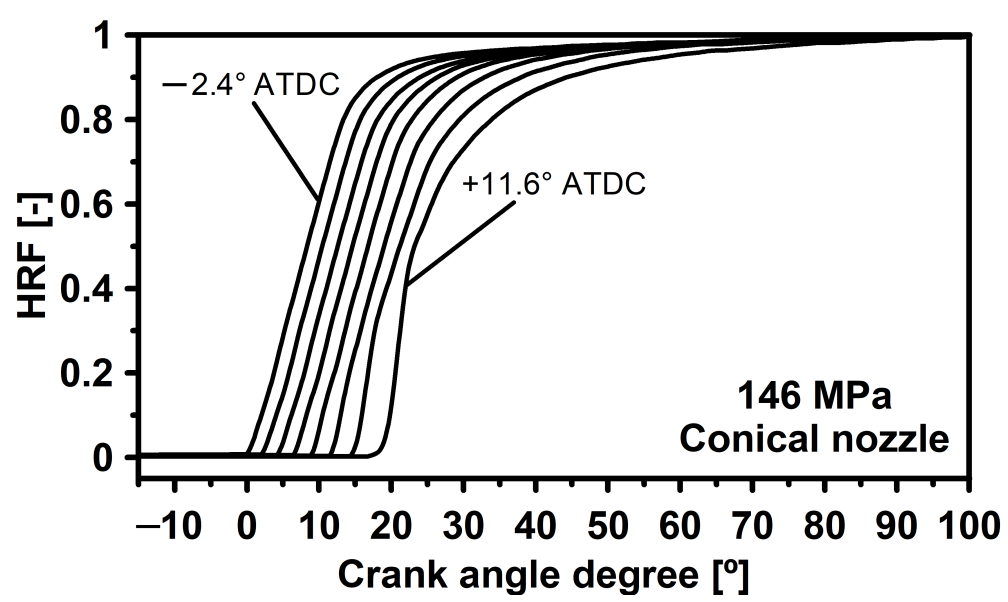

Figure 2. Heat release fraction behaviour as a function of crank angle, for several injection timings when using the conical nozzle and a $p_{\text {rail }}$ level of $146 \mathrm{MPa}$.

As a conclusion, it can be ensured that the oxidation process will be equivalent in two cases with the same $C A 75$, and this will allow us to analyse possible differences in the soot formation process. Figure 3 shows the smoke behaviour versus $C A 75$, for different injection timings when using the conical and cylindrical nozzles and $p_{\text {rail }}$ levels of $76 \mathrm{MPa}$ and $146 \mathrm{MPa}$.

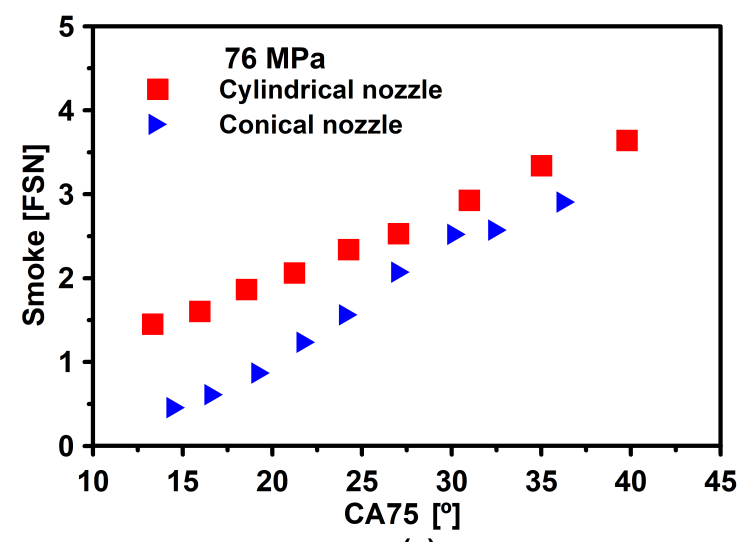

(a)

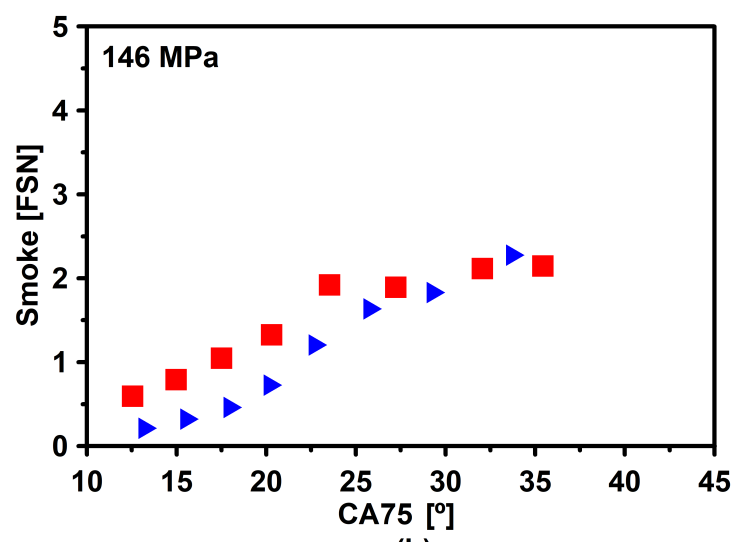

(b)

Figure 3. Smoke behaviour versus $C A 75$, for different injection timings when using the conical and cylindrical nozzles, and $p_{\text {rail }}$ levels of (a) $76 \mathrm{MPa}$ and (b) $146 \mathrm{MPa}$. 


\section{Results and Discussion}

\section{Effects of Cavitation on the Soot Formation Process}

Figure 4 shows the evolution of the $I_{\text {soot }}$ (as was shown in Equation (3)) versus $C A 75$, for several injection timings using the conical and cylindrical nozzles, and for $p_{\text {rail }}$ levels of $76 \mathrm{MPa}$ and $146 \mathrm{MPa}$. Moreover, a fitting curve for $I_{\text {soot }}$ values is also shown in the figure. This fitting was performed up to where both nozzles showed similar behaviour. These fittings were carried out for two reasons: (1), to filter the possible experimental variations and, (2), to obtain values of CA75 not tested through performing interpolation and/or extrapolation. Finally, in Figure 4, a region highlighted with a grey rectangle is also shown, which corresponds to the range where the results will be analysed.

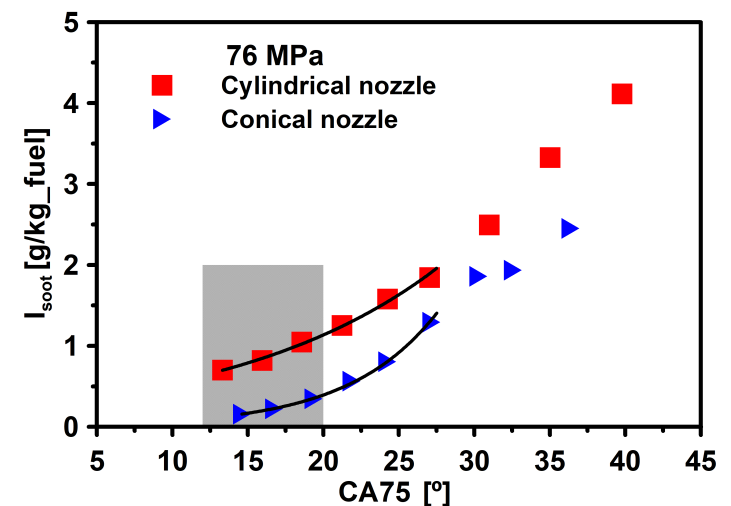

(a)

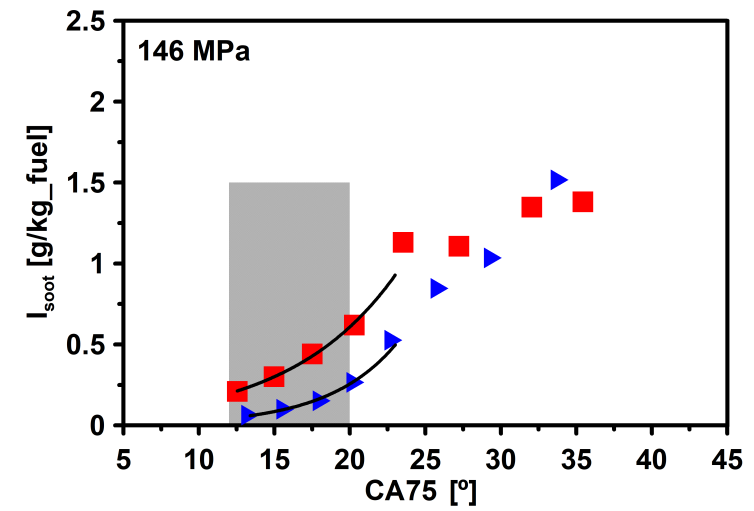

(b)

Figure 4. Evolution of the $I_{\text {soot }}$ versus CA75, for several injection timings using the conical and cylindrical nozzles, and $p_{\text {rail }}$ levels of (a) $76 \mathrm{MPa}$ and (b) $146 \mathrm{MPa}$.

Before analysing the results, it is worthy to highlight that the parameter of higher influence on the soot formation process is the equivalence fuel/air ratio at the lift-off $\left(F_{r L O L}\right)$, as it was mentioned in the introduction section, whose functional dependence is the following [30]:

$$
F_{r L O L} \propto \frac{L_{\text {flame }}}{L O L}
$$

where $L O L$ is the lift-off length, which is defined as the distance from the nozzle orifice exit and the start the flame; $L_{\text {flame }}$ is the flame length, which is defined as the distance from the nozzle orifice exit and the flame tip. The functional dependence is defined by Equation (6) [31]:

$$
L_{\text {flame }} \propto\left[\left(\frac{m_{a}}{m_{f}}\right)_{s t} \cdot \frac{0.23}{Y O_{2}}\right] \cdot d_{e f f} \cdot \sqrt{\frac{\rho_{a}}{\rho_{f}}}
$$

where $\left(m_{a} / m_{f}\right)_{s t}$ is the stoichimetric air-fuel ratio, $Y \mathrm{O}_{2}$ is the oxygen mass fraction, $d_{e f f}$ is the effective diameter, and finally $\rho_{a}$ and $\rho_{f}$ are the air and fuel density, respectively. Considering that most of the terms in Equation (6) are constant when taking them at $C A 75$, the final expression for $L_{\text {flame }}$ is:

$$
L_{\text {flame }} \propto d_{e f f}
$$

Equation (8) is obtained from combination of Equations (5) and (7).

$$
F_{r L O L} \propto \frac{d_{e f f}}{L O L}
$$

where $L O L$ follows the scaling law described by Equation (9) $[32,33]$. 


$$
L O L=K \cdot d_{e f f}^{0.34} \cdot\left(\sqrt{\Delta p} \cdot C_{v}\right) \cdot \rho_{a}^{-0.85} \cdot T_{a}^{-3.74} \cdot Y O_{2}^{-1}
$$

where $K$ is a constant of proportionality, $\left(\sqrt{\Delta p} \cdot C_{v}\right)$ is proportional to the effective injection velocity, and $T_{a}$ is the air temperature. It should be noted that the proportionality constant can differ from one nozzle to the other. As a first approach, the same value will be assumed for both nozzles, and later, in view of the results, this assumption will be revised.

Combining Equations (8) and (9), and considering also that all tests were carried out at the same in-cylinder conditions (air temperature and density, and oxygen mass fraction), and that the comparison will be performed at the same $p_{\text {rail }}$ level, the $F_{r L O L}$ is scaled by Equation (10).

$$
F_{r L O L} \propto \frac{d_{e f f}^{0.66}}{C_{v}}
$$

It is worthy to note that $F_{r L O L}$ is determined employing the $d_{e f f}$ and $C_{v}$ values previously described in Table 4 . Figure 5 a shows the evolution of $I_{s o o t}$ versus $F_{r L O L}$, for different cases with the same $C A 75$, viz. $C A 75=12, C A 75=14, C A 75=16$, and $C A 75=18$, covering the region marked in Figure 4, using the conical and cylindrical nozzles. Whilst, in Figure $5 \mathrm{~b}$, the values of $I_{\text {soot }}$ presented in Figure $5 \mathrm{a}$ are normalized by the value of $I_{\text {soot }}$ from the conical nozzle, hence all values of $I_{\text {soot }}$ for the conical nozzle are 1 . This manner to proceed was already applied systematically in the work preceding this one [24].

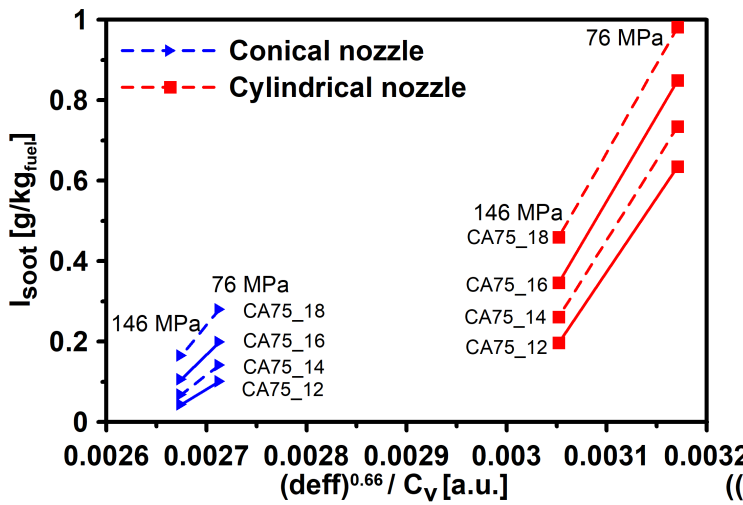

(a)

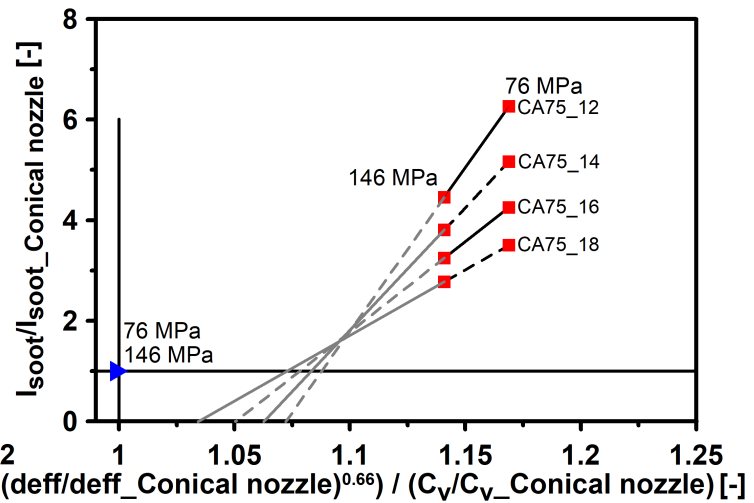

(b)

Figure 5. (a) Evolution of the $I_{\text {soot }}$ versus $F_{r L O L}$, for several cases with the same CA75 using the conical and cylindrical nozzles. (b) The value of $I_{\text {soot }}$ is normalized by the value of $I_{\text {soot }}$ from the conical nozzle.

Despite the complexity involved in the analysis of the final soot emissions, which are the result of a balance between the soot formation process and that of soot oxidation, there are two points to highlight from the results presented in Figure $5 \mathrm{~b}$. For the observation, attention will be focused on the $I_{\text {soot }}$ behaviour in both the conical and cylindrical nozzles, but individually in each of the $p_{\text {rail }}$ levels tested. The two points to highlight are: (1) the cylindrical nozzle produces more soot compared to the conical one. These results were also observed by Kong et al. [34], when they analysed the influence of nozzle geometry on the combustion process using a single-cylinder engine. This behaviour can be attributed to the larger effective diameter of the cylindrical nozzle compared to that of the conical nozzle, which leads to a higher $F_{r L O L}$ [24]. (2) It is noted that, as the cavitation intensity increases in the cylindrical nozzle, which is associated to the $p_{\text {rail }}$ level, the soot formation is reduced.

This behaviour can be due to two reasons: (1) cavitation provokes a reduction in the effective diameter, therefore decreasing the equivalence fuel/air ratio at the lift-off length; (2) it also produces an increase in $C_{v}$, hence increasing the lift-off length and diminishing the corresponding equivalence fuel/air ratio [24]. It is worthy to note that the experimental and analysis methodology used in the present study has allowed isolating the effect of 
cavitation on soot formation from other effects, such as the nozzle diameter or permeability, thus reaching the statements previously described.

Moreover, it can be seen in Figure $5 b$ that, if all straight lines connecting the red dots are extrapolated (see the grey lines), these ones cross the $y=1$ value (i.e., conical nozzle's reference) in $x>1$ values. This indicates that with cavitation, an additional effect takes place, apart from the reduction of $d_{e f f}$ and the increase in $C_{v}$. Thanks to this additional effect, it is possible to have the same soot formation with a higher $d_{e f f}$ or a lower $C_{v}$ than those of the conical nozzle. As already indicated in a previous study by Payri et al. [24], and based on Equation (8), this additional effect can be an increase in the lift-off length provoked by cavitation, which most probably is caused by the higher turbulence level of the flow exiting the nozzle orifice, leading to a stabilization of the lift-off further downstream. In a previous work [24], the hypothesis previously described was first raised and partially confirmed by $L O L$ visualization results. Now, in the present work, with a significantly different approach, the hypothesis appears again, reinforcing its validity a bit more. In other words, this result indicates that the proportionality constant in Equation (9) is not the same for both nozzles. If the correct proportionality constant would be used for each nozzle, the point where all lines converge in Figure $5 b$ would be placed at point $(1,1)$. Based on this, it can be concluded that the $L O L$ increases in a factor of 1.08 when cavitation appears.

\section{Conclusions}

In the present work, the effects of cavitation on the soot formation process through measuring soot emissions, which are the result of a balance between the soot formation process and that of soot oxidation have been explored. To do so, a novel methodology has been employed, which consists in choosing cases with the same $C A 75$, where there is an equivalent soot oxidation process. Hence differences in the soot formation process were possible to be analysed. Now, the main conclusions reached in the present work will be described.

The cylindrical nozzle produces more soot formation compared to the conical nozzle in about $84 \%$ and $77.5 \%$ for the level of $p_{\text {rail }}$ of $76 \mathrm{MPa}$ and $146 \mathrm{MPa}$, respectively. Moreover, as the cavitation intensity increases in the cylindrical nozzle, which is associated with the $p_{\text {rail }}$ level, the soot formation is reduced by about $53.2 \%$ from $76 \mathrm{MPa}$ to $146 \mathrm{MPa}$. This reduction can be attributed by combining results of three effects, namely: a reduction of the effective diameter, an increase in $C_{v}$, and an additional effect observed on the soot formation process when cavitation phenomenon appears, which most probably is related to an increase in turbulence level inside the nozzle orifice; leading to a lift-off length increases in a factor of 1.08. The three effects lead to a reduction in equivalence fuel/air ratio at the lift-off length by about $3.7 \%$, therefore explaining the soot formation reduction.

Author Contributions: Conceptualization, J.J.L. and O.A.d.l.G.; methodology, J.J.L., O.A.d.l.G., and J.D.1.M.; software, J.J.L., O.A.d.l.G., and J.D.1.M.; validation, J.J.L., O.A.d.l.G., and S.M.-M.; formal analysis, J.J.L., O.A.d.1.G., J.D.1.M., and S.M.-M.; investigation, J.J.L. and O.A.d.1.G.; resources, J.J.L., O.A.d.l.G., and S.M.-M.; writing—original draft preparation, J.J.L. and O.A.d.l.G.; writing—review editing, J.J.L. and O.A.d.1.G.; visualization, J.J.L., O.A.d.l.G., and S.M.-M.; supervision: J.J.L.; project administration, J.J.L. and O.A.d.l.G.; funding acquisition, J.J.L. and O.A.d.l.G. All authors have read and agreed to the published version of the manuscript.

Funding: This research was funded by UANL-PAICYT (grant number: IT1829-21), the DENSO North America Foundation (project: Influence of multiple-injection strategies on the injection process using direct-acting piezoelectric and solenoid diesel injector), the FPU program of the Spanish Ministry of Education (grant number: AP2008-01913), and the LaNDACBio (grant number: 315787).

Institutional Review Board Statement: Not applicable.

Informed Consent Statement: Not applicable.

Data Availability Statement: Data sharing not applicable. 
Acknowledgments: The authors would like to thank Gabriel Alcantarilla and Santiago Molina, who are members of CMT-Motores Térmicos, for the support in performing the experimental measurements in the single-cylinder engine.

Conflicts of Interest: The authors declare no conflict of interest.

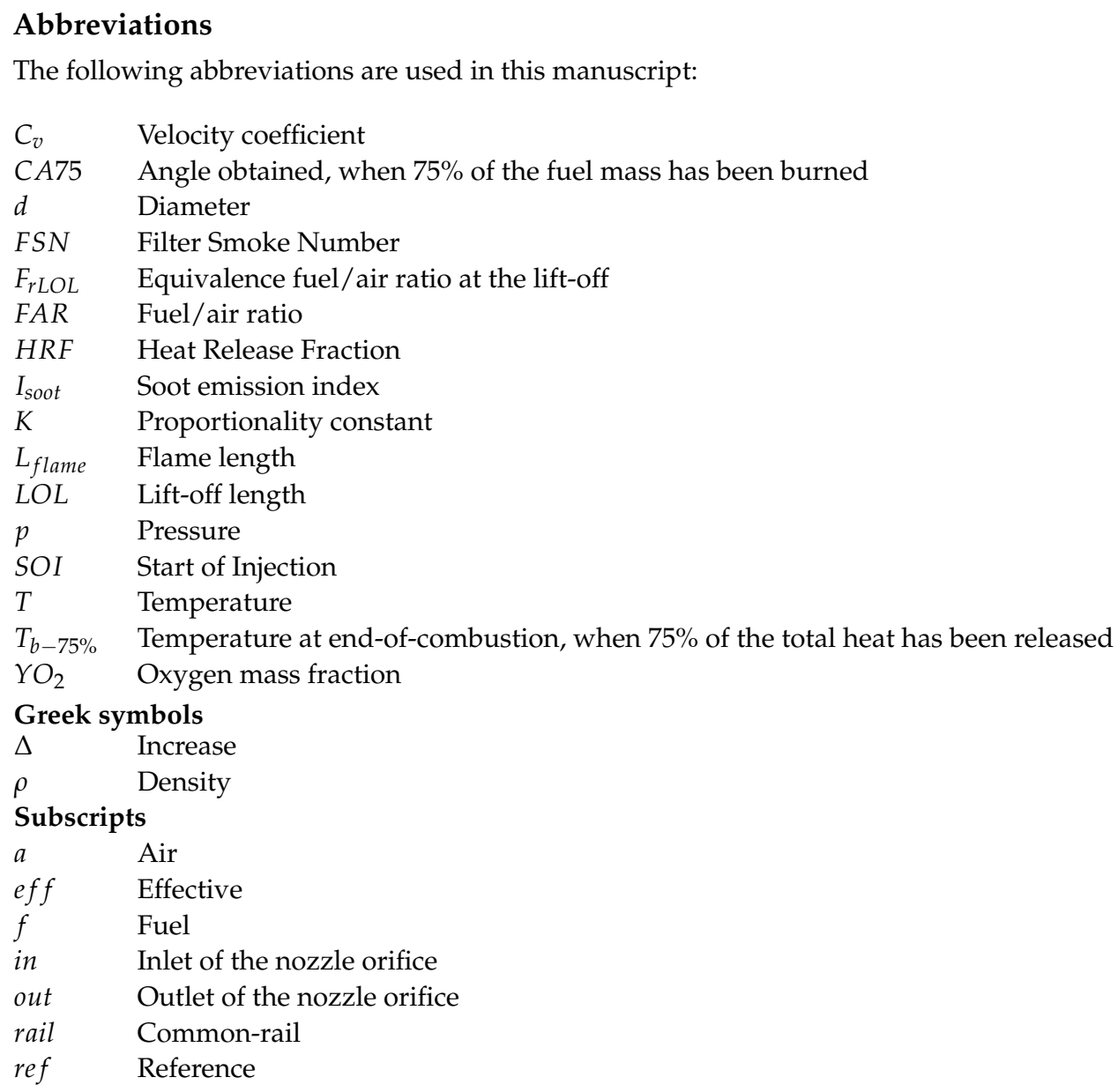

\section{References}

1. Ferraro, F.; Russo, C.; Schmitz, R.; Hasse, C.; Sirignano, M. Experimental and numerical study on the effect of oxymethylene ether-3 (OME3) on soot particle formation. Fuel 2021, 286, 119353. [CrossRef]

2. Bermúdez, V.; García, A.; Villalta, D.; Soto, L. Assessment on the consequences of injection strategies on combustion process and particle size distributions in Euro VI medium-duty diesel engine. Int. J. Engine Res. 2020, 21, 683-697. [CrossRef]

3. Jamrozik, A.; Tutak, W.; Grab-Rogaliński, K. Combustion Stability, Performance and Emission Characteristics of a CI Engine Fueled with Diesel/n-Butanol Blends. Energies 2021, 14, 2817. [CrossRef]

4. Mei, D.; Yu, Q.; Zhang, Z.; Yue, S.; Tu, L. Effects of Two Pilot Injection on Combustion and Emissions in a PCCI Diesel Engine. Energies 2021, 14, 1651. [CrossRef]

5. Fernández-Rodríguez, D.; Lapuerta, M.; German, L. Progress in the Use of Biobutanol Blends in Diesel Engines. Energies 2021, 14, 3215. [CrossRef]

6. Rao, L.; Zhang, Y.; Kook, S.; Kim, K.S.; Kweon, C.B. Understanding the soot reduction associated with injection timing variation in a small-bore diesel engine. Int. J. Engine Res. 2021, 22, 1001-1015. [CrossRef]

7. López, J.J.; Martín, J.; García, A.; Villalta, D.; Warey, A. Implementation of two color method to investigate late cycle soot oxidation process in a CI engine under low load conditions. Appl. Therm. Eng. 2017, 113, 878-890. [CrossRef]

8. Bjørgen, K.O.P.; Emberson, D.R.; Løvås, T. Combustion and soot characteristics of hydrotreated vegetable oil compression-ignited spray flames. Fuel 2020, 266, 116942. [CrossRef]

9. Xu, Z.; Duan, X.; Liu, Y.; Deng, B.; Liu, J. Spray combustion and soot formation characteristics of the acetone-butanolethanol/diesel blends under diesel engine-relevant conditions. Fuel 2020, 280, 118483. [CrossRef]

10. Yraguen, B.F.; Poursadegh, F.; Genzale, C.L. Assessment of engine combustion network recommendations for measurement of ignition and lift-off length. Int. J. Engine Res. 2021, 22, 1838-1849. [CrossRef] 
11. Pastor, J.V.; García, A.; Micó, C.; García-Carrero, A.A. Experimental study of influence of Liquefied Petroleum Gas addition in Hydrotreated Vegetable Oil fuel on ignition delay, flame lift off length and soot emission under diesel-like conditions. Fuel 2020, 260, 116377. [CrossRef]

12. Rao, L.; Zhang, Y.; Kook, S.; Kim, K.S.; Kweon, C.B. Understanding in-cylinder soot reduction in the use of high pressure fuel injection in a small-bore diesel engine. Proc. Combust. Inst. 2019, 37, 4839-4846. [CrossRef]

13. Desantes, J.M.; Garcia-Oliver, J.M.; Novella, R.; Pachano, L. A numerical study of the effect of nozzle diameter on diesel combustion ignition and flame stabilization. Int. J. Engine Res. 2020, 21, 101-121. [CrossRef]

14. Payri, R.; Viera, J.P.; Gopalakrishnan, V.; Szymkowicz, P.G. The effect of nozzle geometry over ignition delay and flame lift-off of reacting direct-injection sprays for three different fuels. Fuel 2017, 199, 76-90. [CrossRef]

15. Pastor, J.V.; García-Oliver, J.M.; López, J.J.; Vera-Tudela, W. An experimental study of the effects of fuel properties on reactive spray evolution using Primary Reference Fuels. Fuel 2016, 163, 260-270. [CrossRef]

16. Cristofaro, M.; Edelbauer, W.; Koukouvinis, P.; Gavaises, M. A numerical study on the effect of cavitation erosion in a diesel injector. Appl. Math. Model. 2020, 78, 200-216. [CrossRef]

17. López, J.J.; de la Garza, O.A.; la Morena, J.D.; Martínez-Martínez, S. Effects of cavitation in common-rail diesel nozzles on the mixing process. Int. J. Engine Res. 2017, 18, 1017-1034. [CrossRef]

18. Salvador, F.J.; de la Morena, J.; Carreres, M.; Jaramillo, D. Numerical analysis of flow characteristics in diesel injector nozzles with convergent-divergent orifices. Proc. Inst. Mech. Eng. Part D J. Automob. Eng. 2017, 231, 1935-1944. [CrossRef]

19. Guo, G.; He, Z.; Zhang, Z.; Duan, L.; Guan, W.; Duan, X.; Jin, Y. Visual experimental investigations of string cavitation and residual bubbles in the diesel nozzle and effects on initial spray structures. Int. J. Engine Res. 2020, 21, 437-447. [CrossRef]

20. Fimml, W.; Chmela, F.G.; Pirker, G.; Wimmer, A. Influence of Cavitation in the Injection Nozzle on Combustion in Diesel Engines. Int. J. Engine Res. 2010, 11, 375-390. [CrossRef]

21. Benajes, J.; Molina, S.; González, C.; Donde, R. The role of nozzle convergence in diesel combustion. Fuel 2008, 87, 1849-1858. [CrossRef]

22. Som, S.; Ramirez, A.I.; Longman, D.E.; Aggarwal, S.K. Effect of nozzle orifice geometry on spray, combustion, and emission characteristics under diesel engine conditions. Fuel 2011, 90, 1267-1276. [CrossRef]

23. Maes, N.; Skeen, S.A.; Bardi, M.; Fitzgerald, R.P.; Malbec, L.M.; Bruneaux, G.; Pickett, L.M.; Yasutomi, K.; Martin, G. Spray penetration, combustion, and soot formation characteristics of the ECN Spray C and Spray D injectors in multiple combustion facilities. Appl. Therm. Eng. 2020, 172, 115136. [CrossRef]

24. Payri, F.; López, J.J.; Garcia, A.; de la Garza, O.A.; Houille, S. Effects of cavitation in common-rail diesel nozzles on the soot formation process. SAE Tech. Pap. 2013, 2. [CrossRef]

25. Macian, V.; Bermúdez, V.; Payri, R.; Gimeno, J. New technique for determination of internal geometry of a diesel nozzle with the use of silicone methodology. Exp. Tech. 2003, 27, 39-43.

26. Olmeda, P.; Martin, J.; Garcia, A.; Villalta, D.; Warey, A.; Domenech, V. A Combination of Swirl Ratio and Injection Strategy to Increase Engine Efficiency. SAE Int. J. Engines 2017, 10. [CrossRef]

27. Molina, S. Influence of Injection Parameters and Exhaust Gas Recirculation on the Combustion Process, Performace, and Emissions in a Diesel Engine of 1.8 Liters. Ph.D. Thesis, Universitat Politècnica de València, Valencia, Spain, 2003. (In Spanish)

28. Christian, R.; Knopf, F.; Jaschek, A.; Schindler, W. A new method for filter smoke number measurement with improved sensitivity. Mot. Z. 1993, 54, 16-22.

29. Payri, F.; Olmeda, P.; Martín, J.; García, A. A complete 0D thermodynamic predictive model for direct injection diesel engines. Appl. Energy 2011, 88, 4632-4641. [CrossRef]

30. López, J.J.; Garcia-Oliver, J.M.; Martin, J.; Chemisky, J.P.; Bouet, A. A soot radiation model for diesel sprays. SAE Tech. Pap. 2012. [CrossRef]

31. Arrégle, J.; López, J.J.; García, J.M.; Fenollosa, C. Development of a zero-dimensional Diesel combustion model. Part 1: Analysis of the quasi-steady diffusion combustion phase. Appl. Therm. Eng. 2003, 23, 1301-1317. [CrossRef]

32. Siebers, D.; Higgins, B. Flame lift-off on direct-injection diesel sprays under quiescent conditions. SAE Tech. Pap. 2001. [CrossRef]

33. Siebers, D.; Higgins, B.; Pickett, L. Flame lift-off on direct-injection diesel fuel jets: Oxygen concentration effects. SAE Tech. Pap. 2002. [CrossRef]

34. Kong, J.; Bea, C. Effect of a conical nozzle orifice of the combustion and emissions in a direct-injection compression ignition engine under low-load conditions. Proc. Inst. Mech. Eng. Part D J. Automob. Eng. 2015, 229, 3-13. [CrossRef] 